\title{
A Comparative Corpus-Based Analysis of Using Hedging, Boostering, and Self-Mentioning Metadiscourse Markers in Persian and English Psychology Books
}

\section{Yousef Karami $^{1 *}$, \& Mehrnoosh Lohran Poor ${ }^{1}$}

* Correspondence:

Yousefkarami1370@gmail.com

1. Department of English Language and

Literature, Ilam University, Iran

Received: 6 September 2019

Revision: 26 November 2019

Accepted: 24 December 2019

Published online: 20 June 2020

\begin{abstract}
Metadiscourse is a set of linguistic ties used to communicate attitudes and denote the grammatical attributes of a text. The present study was conducted to inspect using hedging, boostering, and self-mentioning metadiscourse markers in the well-known Persian and English psychology books. Based on the chosen corpora of the study, this inquiry purposed to realize what the general preferences are in the use of hedging, boostering, and self-mentioning metadiscourse markers in Persian and English psychology books. The corpora of four psychology books, two by Persianspeaking psychologists and two by English-speaking psychologists, were chosen and analyzed based on Hyland's (2005) model of metadiscourse. The data obtained and collected from the chosen corpora were analyzed by Ant Conc 3.5.7 and SPSS statistical software. By analyzing the corpora of the study quantitatively, it is resulted that Persian-speaking psychologists used more metadiscourse markers than that of Englishspeaking psychologists in their books. Secondly, it is detected that Persian-speaking psychologists used fewer hedging metadiscourse markers in their books than that of their English-speaking counterparts. Thirdly, it is found that Persian-speaking psychologists used more boostering metadiscourse markers in their books than that of their Englishspeaking counterparts. Next, it is realized that Persian-speaking psychologists used more singular first-person self-mentioning metadiscourse markers in their books; however, their English-speaking counterparts used more plural third-person self-mentioning metadiscourse markers in their books. In addition, textual analysis has shown the difference of Persian and English sub-corpora in using hedging, boostering, and self-mentioning metadiscourse markers.
\end{abstract}

Keywords: metadiscourse markers, hedge, booster, self-mention, psychology 


\section{Introduction}

Beauvais (1989) has argued that Zellig Harris coined the term "metadiscourse" in order to better state the pragmatic relations between writer and reader several decades ago. According to Hyland (2005), Intaraprawat, and Steffensen (1995), Williams further has developed the concept in his 1981 text, Style: Ten Lessons in Clarity and Grace. Over the past several decades, several classification systems have been expanded for metadiscourse markers since the prime interest in this topic (Beauvais, 1989; Crismore, 1984; Hyland, 2005; Vande Kopple, 1984; 1997; Williams, 1980). As stated by Dafouz-Milne (2008), most of the classifications usually organize the linguistic units under two primary kinds: textual and interpersonal. According to Hyland (2005), metadiscourse comprises the idea that communication is more than just the exchange of information and it also includes the characters, tendencies, and assumptions of those who are communicating. Also, Toumi (2009) has discussed that metadiscourse plays an accurate role in academic discourse. It has beard a substantial social meaning by disclosing the author's character and identity and by showing how he expects his readers to respond to his suggestions.

Hyland (1998) has defined metadiscourse as a common term to comprise many diverse types of attributes which assist relate a text to its context by helping readers to connect, form, and expound material in a way preferred by the writer and with regard to the realizations and values of a specific discourse society. Likewise, it refers to the linguistic ties writers utilize to shape their logics to the necessities and expectations of their target readers. As clarified by Hui and $\mathrm{Na}(2008)$ when we talk about the use of metadiscourse in a text, we refer to metadiscourse specifications. They are simply those linguistic markers which, while not particularly required to the issue, show that the writer is aware of the demands of the audience to communicate the semantic content.

The likely most precise framework for the study of metadiscourse is provided by Hyland (2005). He has categorized metadiscourse into interactive and interactional metadiscourse. Interactive metadiscourse referred to those markers in which used to form propositional information in ways that a planned target audience is probably to detect coherence and convincing. It includes five features of transitions, frame markers, endophoric markers, evidentials, and code glosses. The interactional metadiscourse considered the ways writers administered interaction by intruding and interpreting on their message. It contains five features of hedges, boosters, attitude markers, engagement markers, and self-mentions. The details of Hyland's categorization are showed in Table 1 below.

Table 1. An interpersonal model of metadiscourse (Hyland, 2005)

\begin{tabular}{|c|c|c|}
\hline Category & Function & Examples \\
\hline Interactive resources & Help to guide reader through the text & \\
\hline Transitions & $\begin{array}{l}\text { Express semantic relation between main } \\
\text { clauses }\end{array}$ & In addition/ but/ thus/ and \\
\hline Frame markers & $\begin{array}{l}\text { Refer to discourse acts, sequences, or } \\
\text { stages }\end{array}$ & Finally/ to conclude/ my purpose is \\
\hline Endophoric markers & $\begin{array}{l}\text { Refer to information in other parts of } \\
\text { the text }\end{array}$ & Noted above/ see Fig/ in section 2 \\
\hline Evidentials & $\begin{array}{l}\text { Refer to source of information from } \\
\text { other texts }\end{array}$ & according to $\mathrm{X} /(\mathrm{Y}, 1990) / \mathrm{Z}$ states \\
\hline Code glosses & $\begin{array}{l}\text { Help readers grasp meanings of } \\
\text { ideational material }\end{array}$ & Namely/ e.g./ such as/ in other words \\
\hline Interactional resources & Involve the reader in the argument & Examples \\
\hline Hedges & $\begin{array}{l}\text { Withhold writer's full commitment to } \\
\text { proposition }\end{array}$ & Might/ perhaps/ possible/ about \\
\hline Boosters & $\begin{array}{l}\text { Emphasize force or writer's certainty in } \\
\text { proposition }\end{array}$ & In fact/ definitely/ it is clear that \\
\hline
\end{tabular}


Attitude markers

Engagement markers
Express writer's attitude to proposition

Explicitly refer to or build relationship with reader

Explicit reference to author(s)
Unfortunately/ I agree/ surprisingly

Consider/ note that/ you can see that

I/ we/ my/our

Self-mentions

\subsection{Statement of the Problem}

Many studies have been carried out on metadiscourse markers (Gholami \& Ilghami, 2016; Gholami, Tajalli, \& Shokrpour, 2014; Kim \& Suh, 2014); however, no attention has been paid to concentrate on a comparative study of using hedging, boostering, and self-mentioning metadiscourse markers in Persian and English psychology books. This study seeks to remedy this shortcoming by analyzing four well-known Persian and English psychology books. The primary aim of this comparative study is therefore to investigate the preference of using hedging, boostering, and selfmentioning metadiscourse markers in Persian and English psychology books (written discourse) from a sociocultural standpoint.

\subsection{Research Questions}

The current study purposes to answer the following research questions:

1. Is there any statistically significant difference in using hedging metadiscourse markers in Persian and English Psychology books?

2. Is there any statistically significant difference in using boostering metadiscourse markers in Persian and English Psychology books?

3. Is there any statistically significant difference in using self-mentioning metadiscourse markers in Persian and English Psychology books?

\subsection{Research Hypotheses}

This study seeks to address the following research hypotheses:

1. There is statistically significant difference in using hedging metadiscourse markers in Persian and English Psychology books.

2. There is statistically significant difference in using boostering metadiscourse markers in Persian and English Psychology books.

3. There is not any statistically significant difference in using self-mentioning metadiscourse markers in Persian and English Psychology books.

\section{Literature Review}

According to Hyland (2005), hedges showed the writer's intention to diagnose other voices, standpoints, or probabilities and they were apparently open to negotiate with the reader. As stated by Hyland (2005), boosters have permitted the writer to foresee and prevent alternative and contradictory logics by showing certainty instead of doubt. It is indicated that self-mentions referred to obvious authorial attendance in the text and gave information about his/her personality and stance. Marandi (2003) has inquired the use of metadiscourse markers in the introduction and discussion sections of 30 master dissertations written by Persian and English speakers. She compared three types of text written by British English writers, Persian Iranian writers, and English Iranian writers. After that, he broke down the first 1000 vocabularies in each introduction and discussion sections of the master dissertations to recognize the scope and the subcategories of metadiscourse markers. It is found that in introductions, the textual metadiscourse subgroups were used remarkably; however, in the discussion section, interpersonal metadiscourse subcategory was used more. Moreover, the findings have indicated that the native speakers of Persian applied logical and connectors more than the native speakers of English. 
Dahl (2004) has investigated the use of metadiscourse markers in academic papers. Dahl inquired writings written by English, Norwegian, and French writers in three diverse fields of economics, linguistics, and medicine to observe which factor, academic field or culture, often impacted the use of metadiscourse markers. It is detected that language and culture factor was the most significant in economics and linguistics since English and Norwegian writers made use of metatext more than French writers. On the other hand, in the field of medicine, national culture is revealed to be more substantial than language factor, since a constant structure of introduction, method, results, and discussions is used universally. Yang (2006) has concentrated on a corpus of 10 texts in material science field, probed the use of hedging markers both by Chinese and English writers. It is detected that academic papers written by Chinese writers tend to be more direct and authoritative in tone which may be associated to the nature of the language in that essential field.

Falahati (2006) has done a study to review the research articles' introduction and discussion sections for analyzing the distribution of hedges in these parts. At first, it was detected that hedging distribution is not similar in these sections. Moreover, it was found that the discussion sections comprise more hedging than the introduction ones. The logic for such a difference is that every part of a research article traces a specific direction and has a particular purpose. The introduction part presents the statement of the problem, previous studies, and the reason why to study the present issue while in the discussion part, all of the parts are summarized, calculated, and compared to other studies performed in advance.

Zarei and Mansoori (2007) have probed the metadiscursive types within Persian and English languages in computer engineering and applied linguistics. It is discovered that both English and Persian languages underscored text coherence over interpersonal functions of language. Also, the findings have demonstrated more presuppositions in Persian texts and as a result much of the meaning left to be detected by the reader. Atai and Sadr (2008) have investigated the effect of language and culture on the use of hedging markers in the discussion section of the linguistics academic papers written by English and Persian native speakers. It is found that there were considerable discrepancies in the use of hedging markers by English and Persian native speakers. Likewise, it is disclosed that English native speakers used a diversity of desperate hedging markers in comparison to Persian native speakers.

Zarei and Mansoori (2011) have studied the use of metadiscourse markers in two fields of applied linguistics and computer engineering within both Persian and English languages. Analysis of existing data indicated that the metadiscursive sources were used diversely both within and between the two languages. It is asserted that humanities concentrated on the textuality to the loss of reader involvement. Hu and Cao (2011) have compared hedges and boosters used in the abstracts of English and Chinese applied linguistic articles on the basis of a corpora of 649 abstracts. Their findings have disclosed that abstracts of English articles used more hedges than abstracts of Chinese articles did. Furthermore, this study has indicated that the diverse patterns of hedges and boosters in Chinese and English abstracts had affections on the expression of authorial certainty and confidence.

Tavakoli, Amirian, and Moslemi (2012) have carried out a study to analyze variation and distribution of interactional metadiscourse markers across applied linguistics sub-disciplines of English language teaching, English literature, and English translation. Therefore, they have detected that the frequency of metadiscourse markers was diverse across the articles of English translation, English literature, and English language teaching. Pooresfahani, Khajavy, and Vahidnia (2012) have inquired the use of interactive and interactional metadiscourse markers in two fields of applied linguistics and engineering. The corpus was 8 academic papers of engineering field and 8 articles of applied linguistics. The findings have displayed that in both fields, writers used an interactive metadiscourse marker more than an interactional metadiscourse marker. Furthermore, it is detected that there were personal diversities in interactive and interactional attributes, e.g. engineering writers used more code glosses and endophoric markers, and less sequences and topicalizers than applied linguistics writers. In addition, engineering writers have used more hedges and self-mentions, and less attitude markers and boosters than applied linguistics writers.

Khedri, Ebrahimi, and SweeHeng (2013) have probed the interactional metadiscourse devices in the finding and discussion sections of academic papers through four fields of English language, teaching, civil engineering, biology, and economics. In this study, sixteen result and discussion sections of academic papers were chosen from Leading Interactional Journals and analyzed. The results have represented that there were not statistically remarkable diversities, but boosters between fields in the use of interactional metadiscourse devices. Kuhia and Mojood (2014) have conducted a study on the distribution of metadiscourse features in English and Persian editorials. For this aim, they considered Hyland's model of metadiscourse features and chose 60 news editorials ( 30 in each language) via 
internet. The findings of the study have represented that in both corpora the interactional metadiscourse features were used more frequently as compared to interactive ones. In addition, in interactive dimension, the transition markers were the most repeated one as compared to attitude markers in interactional one.

Ghahremani Mina and Biria (2017) have investigated the use of interactive and interactional metadiscourse markers in discussion parts of social and medical science articles. They chose a targeted sample of 100 English academic papers written by Iranian writers to recognize interactive and interactional metadiscourse markers. It is found that, in interactive metadiscourse category, the use of transitions, frame markers, and evidentials in social science articles were more reiterated than those in medical science texts. Furthermore, they have discovered that the use of endophoric devices and code glosses were almost the same. However, in interactional metadiscourse corpora, the results have shown that writers used hedges, boosters, and self-mentions more frequently in medical science articles compared to those in social sciences. In addition, the discussion parts in social science texts have included a higher percent of engagement markers. It is also detected out that there was no basic diversity in the use of attitude devices in both disciplines. Finally, the authors of social science have apparently preferred to use interactive metadiscourse devices more, while the medical science authors used interactional metadiscourse devices more frequently in their research articles.

Deliery Moghadam (2017) has done a research on the way native speakers of English and Iranian non-native speakers of English put the propositions by using metadiscourse feature in news articles. Considering Hyland's model of metadiscourse features, she chose 60 newspapers from American and Iranian newspapers (30 from each language). By analyzing the corpora quantitatively, she has concluded that the American writers used more metadiscourse features (both interactive and interactional) in their writings. Jomaa and Alia (2019) have inspected functional analyses of metadiscourse devices in L2 students' academic writing. They analyzed the repetition and wordings of modality within the citations of the literature review chapters of $20 \mathrm{Ph}$.D. theses by using the Systemic Functional Linguistics. The results have detected the dominance of full declarative clauses in both Applied Linguistics and Information Technology. Moreover, the Finite Modal Operators, Mood Adjuncts, and Comment Adjuncts were also employed to show modality with a diversity in their stance, degrees, and frequencies. Pedagogically, the obtained results could help supervisors in recognizing the implications of their students' writings. Eventually, studies can be conducted towards reading EAP textbooks and materials that are dedicated to areas of academic writing, metadiscourse markers, and citations.

\section{Methodology}

\subsection{Corpus of the Study}

The corpora of the study included the well-known psychology books of "Paranoia" by Ghahari and Zarghami (2007), "Diagnosis of Schizophrenia" by Peyvastegar (2012), "Paranoia" by Oldham and Bone (1994), and "The Protest Psychosis: How Schizophrenia Became a Black Disease" by Metzl (2011). To make equal sub-corpora, we focused on Persian and English psychology books only. The selection of the corpora was based on direct interviews, indirect interviews, and telephone conversations with Iranian psychologists so as to ensure the precision and validity of the chosen corpora. It comprised of 4 Persian and English psychology books (Persian=2, English=2) and the chosen corpora were published during 1994 to 2012, as indicated in Table 2 below.

Table 2. Description of the corpora

\begin{tabular}{lll}
\hline & Persian sub-corpus & English sub-corpus \\
\hline Number of books & 2 & 2 \\
Length of books (range) & $23,000-28,000$ & $25,000-29,000$ \\
Average Length of books & 25,738 & 27,458 \\
Total number of tokens & 51,476 & 54.916 \\
\hline
\end{tabular}




\subsection{Instruments}

As it was mentioned in previous sections, an interpersonal model of Hyland (2005) was engaged as an instrument to analyze hedging, boostering, and self-mentioning interactional metadiscourse markers in four Persian and English psychology books to reveal the preferences of using hedging, boostering, and self-mentioning interactional metadiscourse markers. The model of Hyland (2005) is shown in Table 1 above. Also, Ant Conc 3.5.7 was used as an instrument to compute the repetition of all metadiscourse elements in both Persian and English sub-corpura. Moreover, the SPSS statistics software was used as an instrument to see whether the significant relationship exists in using metadiscourse markers in both Persian-speaking and English-speaking contexts.

\subsection{Data Collection}

It lasted about three months to collect the data specifically. In doing so, a list of Persian and English metadiscourse elements was provided as a coding scheme. The English one was based on the list of English metadiscourse markers collected by Hyland (2005). Since there was no existing list of Persian metadiscourse devices, we preliminarily translated many English metadiscourse devices into their Persian equivalents and read through the corpus accurately in looking for more feasible metadiscourse elements.

\subsection{Data Analysis}

It took about one month to analyze the obtained data statistically. In doing so, all the words in the classification were searched and signed electronically in the whole corpus so that the total number of tokens of that particular attribute was obtained. Once retrieved, each token was attentively analyzed in context to ensure that it really functioned as a metadiscourse element. Then, Ant Conc 3.5.7 was used to compute the frequency of all metadiscourse elements in both Persian and English sub-corpura according to the labeling. Because the total number of words of each corpus was not equal, we enumerated the frequency of each metadiscourse element per 10,000 words, and compared the regarded metadiscourse markers of the study in the two sub-corpora with SPSS statistics software to see whether the significance exists (One-Sample T-test, Sig < 0.05).

\section{Findings}

The captured data of the corpus was analyzed attentively by SPSS statistics software. At first, the frequency of using each considered hedging, boostering, and self-mentioning metadiscourse markers by Persian-speaking and Englishspeaking psychologists is analyzed and indicated in Tables 3 and 4 below. Secondly, the captured data of the study are analyzed in Table 5 below by one-sample T-test to observe whether the importance exists (One-Sample T-test, Sig $<0.05)$. After all, the comparative analysis of using hedging, boostering, and self-mentioning metadiscourse elements in both Persian-speaking and English-speaking contexts are showed in Figures 1 and 2 below.

Table 3. The frequency distribution of using hedging, boostering, and self-mentioning Persian metadiscourse markers

\begin{tabular}{llllll}
\hline \multicolumn{1}{l}{ Persian Metadiscourse Markers } & & \\
& & Frequency & Percent & $\begin{array}{l}\text { Valid } \\
\text { Percent }\end{array}$ & Cumulative Percent \\
\hline Valid & Hedges & 1544 & 35.0 & 35.9 & 35.9 \\
& Boosters & 1925 & 43.7 & 44.7 & 80.6 \\
& Self- & 833 & 18.9 & 19.4 & 100.0 \\
& mentions & & & & \\
Missing & Total & 4302 & 97.6 & 100.0 & \\
Total & & 105 & 2.4 & & \\
& & 4407 & 100.0 & & \\
\end{tabular}


Table 4. The frequency distribution of using hedging, boostering, and self-mentioning English metadiscourse markers

\begin{tabular}{llllll}
\hline \multicolumn{2}{l}{ English Metadiscourse Markers } & & & & \\
& & Frequency & Percent & Valid Percent & Cumulative Percent \\
\hline Valid & Hedges & 1803 & 40.9 & 43.8 & 43.8 \\
& Boosters & 1673 & 38.0 & 40.7 & 84.5 \\
& Self-mentions & 637 & 14.5 & 15.5 & 100.0 \\
& Total & 4113 & 93.3 & 100.0 & \\
Missing & System & 294 & 6.7 & & \\
Total & & 4407 & 100.0 & & \\
\hline
\end{tabular}

Table 5. One-Sample T-test

One-Sample Test

Test Value $=0$

95\% Confidence Interval of the

Difference

\begin{tabular}{lllllll} 
& \multicolumn{1}{c}{$\mathrm{t}$} & $\mathrm{df}$ & $\mathrm{S}$ Sig. (2-tailed) & Mean Difference & Lower & Upper \\
\hline $\begin{array}{l}\text { Persian } \\
\text { Markers }\end{array}$ & Metadiscourse166.030 & 4301 & .000 & 1.835 & 1.81 & 1.86 \\
$\begin{array}{l}\text { English } \\
\text { Markers }\end{array}$ & Metadiscourse153.698 & 4112 & .000 & 1.717 & 1.69 & 1.74 \\
\hline
\end{tabular}

As shown in Tables 3 and 4 above, Persian-speaking psychologists used more metadiscourse markers than that of English-speaking psychologists in their books. Also, based on Table 5 above, there is a significant relationship (OneSample T-test, Sig < 0.05) in using metadiscourse markers in both Persian-speaking and English-speaking contexts. For better understanding of the above-mentioned data analysis, the comparative analysis of using hedging, boostering, and self-mentioning metadiscourse elements in both Persian-speaking and English-speaking contexts are showed in Figures 1 and 2 below. In addition, the frequency distribution of using instances of hedging, boostering, and selfmentioning metadiscourse markers in Persian-speaking and English-speaking contexts are shown in Figures 3, 4, 5, 6,7 , and 8 (Appendix I). 


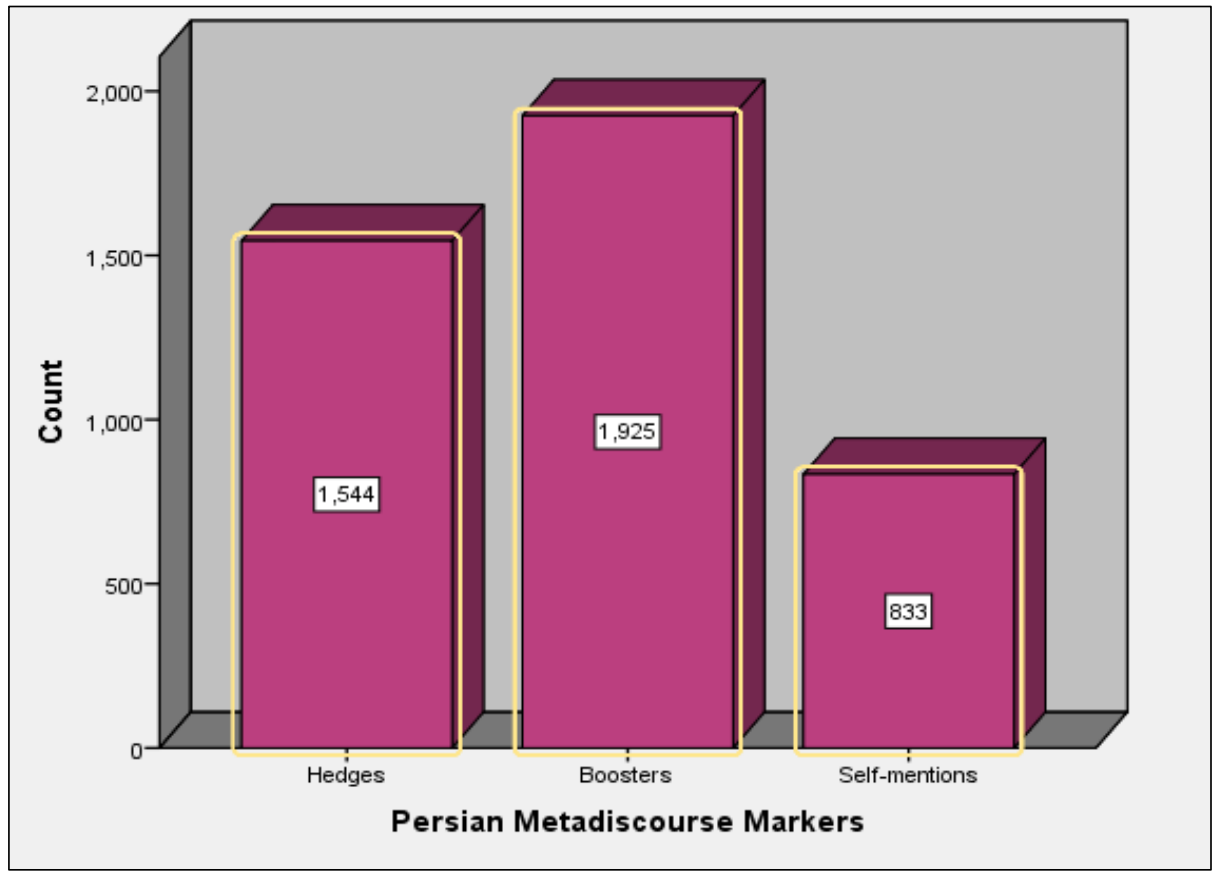

Figure 1. The frequency distribution of using hedging, boostering, and self-mentioning metadiscourse markers in Persian-speaking context

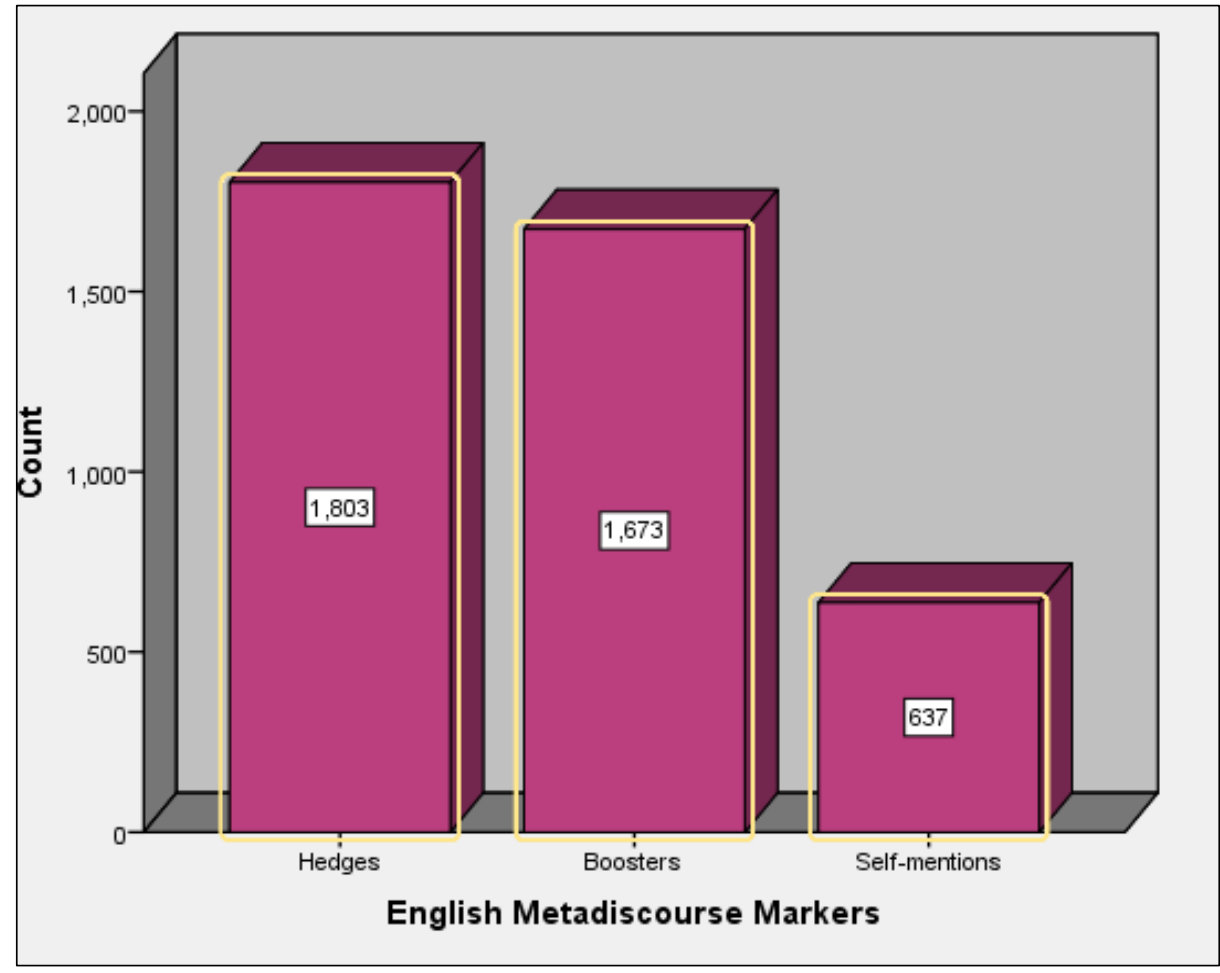

Figure 2. The frequency distribution of using hedging, boostering, and self-mentioning metadiscourse markers in English-speaking context 
Considering the first research question, Persian-speaking psychologists used fewer hedging metadiscourse markers than that of English-speaking psychologists in their books, as demonstrated in Figures 1 and 2 above. Persian-speaking psychologists used 1544 hedging metadiscourse markers in their books and their counterparts used 1803 hedging metadiscourse elements in their books. Thus, there was a significant difference in using hedging metadiscourse markers in Persian and English psychology books.

Considering the second research question, Persian-speaking psychologists used more boostering metadiscourse elements than that of English-speaking psychologists in their books, as showed in Figures 1 and 2 above. Persianspeaking psychologists used 1925 boostering metadiscourse markers in their books and their counterparts used 1673 boostering metadiscourse elements in their books. Therefore, there was a significant difference in using boostering metadiscourse markers in Persian and English psychology books.

Considering the third research question, Persian-speaking psychologists used more self-mentioning metadiscourse markers than that of English-speaking psychologists in their books, as shown in Figures 1 and 2 above. Persianspeaking psychologists used 833 self-mentioning metadiscourse markers in their books and their English-speaking counterparts used 637 self-mentioning metadiscourse elements in their books. So, there was a significant difference in using self-mentioning metadiscourse markers in Persian and English psychology books.

\section{Discussion}

The current study aimed at detecting the preferences of using hedging, boostering, and self-mentioning interactional metadiscourse markers based on Hyland (2005) interpersonal taxonomy in four well-known psychology books written by Persian-speaking and English-speaking psychologists. Referring to the data analysis, the answers of the research questions were obtained. Based on the captured results of the SPSS statistical software, there was a significant relationship (One-Sample T-test, Sig < 0.05) in using metadiscourse markers in both Persian-speaking and Englishspeaking contexts. As obtained findings displayed, Persian-speaking psychologists used more boostering and selfmentioning metadiscourse markers than that of English-speaking psychologists in their books. Also, Persian-speaking psychologists used less hedging metadiscourse markers than that of their English-speaking counterparts.

According to the obtained and analyzed data of the corpora of the study, Persian-speaking psychologists used fewer hedging metadiscourse markers than that of English-speaking psychologists in their books, as exhibited in Figures 1 and 2 above. Persian-speaking psychologists used 1544 hedging metadiscourse markers in their books and their English-speaking counterparts used 1803 hedging metadiscourse elements in their books. Therefore, there was a significant difference in using hedging metadiscourse markers in Persian and English psychology books. More particularly, in Persian-speaking context, the hedging metadiscourse instance of 'may' had the most repetition with 432 times frequency and the hedging metadiscourse instance of 'doubt' had the fewest repetition with 148 times frequency. The hedging metadiscourse instances of 'seem', 'likely', 'almost', and 'guess' were in the second to fifth ranks with 341, 237, 203, and 183 times frequency respectively (Appendix I). In English-speaking context, the hedging metadiscourse instance of 'unusual' had the most repetition with 447 times frequency and the hedging metadiscourse instance of 'plausible' had the fewest repetition with 38 times frequency. The hedging metadiscourse instances of 'likely', 'guess', 'perhaps', 'may', 'seem', and 'probably' were in the second to seventh ranks with 352, 289, 253, 185, 115, and 124 times frequency in sequence (Appendix I).

According to the obtained and analyzed data of the corpora of the study, Persian-speaking psychologists used more boostering metadiscourse elements than that of English-speaking psychologists in their books, as showed in Figures 1 and 2 above. Persian-speaking psychologists used 1925 boostering metadiscourse markers in their books and their English-speaking counterparts used 1673 boostering metadiscourse elements in their books. Therefore, there was a significant difference in using boostering metadiscourse markers in Persian and English psychology books. More specifically, in Persian-speaking context, the boostering metadiscourse instance of 'doubtless' had the most repetition with 538 times frequency and the boostering metadiscourse instance of 'obvious' had the fewest repetition with 116 times frequency. The boostering metadiscourse instances of 'really', 'truly', 'definitely', and 'certain' were in the second to fifth ranks with 481, 397, 231, and 162 times frequency respectively (Appendix I). In English-speaking context, the boostering metadiscourse instance of 'truly' had the most repetition with 405 times frequency and the boostering metadiscourse instance of 'definitely' had the fewest repetition with 98 times frequency. The boostering metadiscourse instances of 'certain', 'prove', 'obvious', 'doubtless', and 'really' were in the second to sixth ranks with 389, 291, 193, 174, and 123 times frequency in sequence (Appendix I). 
According to the obtained and analyzed data of the corpora of the study, Persian-speaking psychologists used more self-mentioning metadiscourse markers than that of English-speaking psychologists in their books, as showed in Figures 1 and 2 above. Persian-speaking psychologists used 833 self-mentioning metadiscourse markers in their books and their counterparts used 637 self-mentioning metadiscourse elements in their books. So, there was a significant difference in using self-mentioning metadiscourse markers in Persian and English psychology books. More particularly, in Persian-speaking context, the self-mentioning metadiscourse instance of 'I' had the most repetition with 306 times frequency and the self-mentioning metadiscourse instance of 'us' had the fewest repetition with 37 times frequency. The self-mentioning metadiscourse instances of 'my', 'me', 'we', and 'our' were in the second to fifth ranks with 213, 118, 95, and 64 times frequency orderly (Appendix I). In English-speaking context, the selfmentioning metadiscourse instance of 'we' had the most repetition with 218 times frequency and the self-mentioning metadiscourse instance of 'me' had the fewest repetition with 54 times frequency. The self-mentioning metadiscourse instances of 'our', 'us', 'I', and 'mine' were in the second to fifth ranks with 124, 95, 81, and 61 times frequency respectively (Appendix I).

The findings of this study are in line with the results of the study conducted by Samaie, Khosravian, and Boghayeri (2014). In this study, English-speaking authors used more hedging metadiscourse markers than their Persian-speaking counterparts. In addition, the results of this study iare in line with the finding of the study carried out by Yazdani, Sharifi, and Elyassi (2014). English-speaking authors used more hedging metadiscourse markers than their Persianspeaking counterparts. However, this study is contrary to the findings of their study that indicated Persian-speaking authors used less interactional boostering and self-mentioning metadiscourse markers than their English-speaking counterparts.

The results of this study are in line with the result of the study performed by Karimi, Maleki, and Farnia (2017). English-speaking authors used more hedging metadiscourse markers than their Persian-speaking ones. But, the findings of the current study are contrary to the results of their research that showed English-speaking authors used more interactional boostering and self-mentioning metadiscourse markers than their Persian-speaking ones. Also, the results of this study are in line with the finding of the study done by Ebadi, Rawdhan Salman, and Ebrahimi (2015). English-speaking authors applied more hedging metadiscourse markers than their Persian-speaking counterparts. But, the findings of the present study are contrary to the results of their study that showed English-speaking authors used more interactional boostering and self-mentioning metadiscourse markers than their Persian-speaking ones.

\section{Conclusion}

According to Amiryousefi and Eslami Rasekh (2010), metadiscourse has played an important role in making persuasive writings on the basis of the people's expectations and norms; therefore, it is regarded as a novel and interesting field of research. Hyland (2005) has regarded metadiscourse as a concept of interaction among the writer/speaker with their texts from one side and between them and hearer/reader from another side. To sum, firstly, Persian-speaking psychologists used more metadiscourse markers than that of English-speaking psychologists in their books. Secondly, Persian-speaking psychologists used fewer hedging metadiscourse markers in their books than that of their English-speaking counterparts. Thirdly, Persian-speaking psychologists used more boostering metadiscourse markers in their books than that of their English-speaking counterparts. Fourthly, Persian-speaking psychologists generally used more self-mentioning metadiscourse markers than that of their English-speaking counterparts. Fifthly, Persian-speaking psychologists specifically used more singular first-person self-mentioning metadiscourse markers in their books; however, their English-speaking counterparts used more plural third-person self-mentioning metadiscourse markers in their books. Therefore, the first and second hypotheses of the study can be confirmed since the findings showed that there is a significant difference in using hedging and boostering metadiscourse markers in Persian and English Psychology books. And, the third hypothesis cannot be confirmed because the results indicated that there is a significant difference in using self-mentioning metadiscourse markers in the chosen corpora.

To close, Persian-speaking psychologists used mostly certain words in recognizing and treating mental patients' illnesses, but their English-speaking counterparts used often the uncertain words in recognizing and treating mental patients' illnesses; therefore, unlike the Persian-speaking psychologists, English-speaking psychologists used more plural third-person self-mentioning metadiscourse markers while treating mental patients to show cooperation has a more positive reflection in treating mental patients than doing the best by psychologists to treat the patients and ignoring the patients to be treated. To direct any kind of scientific study, one may face with some limitations. The current study could have attained rather different results if it had not faced with the following constraints. The 
limitation that should be addressed mentioning the study is the limited number of the corpora of the study. Therefore, it is suggested that the present study be reiterated with a larger corpus to see if similar findings will be achieved.

\section{References}

Amiryousefi, M., \& Eslami-Rasekh, A. (2010). Metadiscourse: Definitions, issues, and its implications for English teachers. English Language Teaching, 3(4), 159-167. http://dx.doi.org/10.5539/elt.v3n4p159

Atai, M. R., \& Sadr, L. (2008). A cross-cultural study of hedging devices in discussion section of applied linguistics research articles. Teaching English Language (Teaching English Language and Literature Society of Iran), 2(7), 1-22. https://www.sid.ir/en/journal/ViewPaper.aspx?ID=162198

Beauvais, P. J. (1989). A speech act theory of metadiscourse. Written communication, 6(1), 11-30. https://doi.org/10.1177/0741088389006001002

Crismore, A. (1984). The rhetoric of textbooks: Metadiscourse. J. Curriculum Studies, 16(3), 279-296. https://doi.org/10.1177/0741088389006001002

Dafouz-Milne, E. (2008). The pragmatic role of textual and interpersonal metadiscourse markers in the construction and attainment of persuasion: A cross-linguistic study of newspaper discourse. Journal of Pragmatics, 40(1), 95113. https://doi.org/10.1016/j.pragma.2007.10.003

Dahl, T. (2004). Textual metadiscourse in research articles: a marker of national culture or of academic discipline? Journal of Pragmatics, 36(10), 1807-1825. https://doi.org/10.1016/j.pragma.2004.05.004

Ebadi, S., Rawdhan, A. S., \& Marjal, B. E. (2015). A comparative study of the use of metadiscourse markers in Persian and English academic papers. Journal of Applied Linguistics and Language Research, 2(4), 28-41. https://www.researchgate.net/publication/276028305_A_Comparative_Study_of_the_Use_of_Metadicourse_ Markers_in_Persian_and_English_Academic_Papers

Falahati, R. (2006). The use of hedging across different disciplines and rhetorical sections of research articles. Proceedings of the 22nd North West Linguistics Conference (NWLC22), Burnaby: Simon Fraser University, 1, 99-112.

Ghahari, S. H., \& Zarghami, M. (2007). Schizophrenia .Tehran: Qhatre Publication.

Ghahremani Mina, K., \& Biria, R. (2017). Exploring interactive and interactional metadiscourse markers in discussion sections of social and medical science articles. International Journal of Research in English Education, 2(4), 1129. http://ijreeonline.com/article-1-71-en.html

Gholami, J., \& Ilghami, R. (2016). Metadiscourse markers in biological research articles and journal impact factor: Non-native writers vs. native writers. Biochem. Mol. Biol. Educ., 44(4), 349-360. doi:10.1002/bmb.20961

Gholami, M., Tajalli, G., \& Shokrpour, N. (2014). An investigation of metadiscourse markers in English medical texts and their Persian translation based on Hyland's model. European Journal of English Language and Literature Studies, 2(2), 1-41. http://www.eajournals.org/wp-content/uploads/An-Investigation-Of-MetadiscourseMarkers-In-English-Medical-Texts-And-Their-Persian-Translation-Based-On-Hylands-Model2.pdf

Hu, G., \& Cao, F. (2011). Hedging and boosting in abstracts of applied linguistics articles: A comparative study of English-and Chinese-medium journals. Journal of pragmatics, 43(11), 2795-2809. https://doi.org/10.1016/j.pragma.2011.04.007

Hyland, K. (1998). Hedging in scientific research articles (Vol. 54). John Benjamins Publishing. doi: https://doi.org/10.1075/pbns.54

Hyland, K. (2005). Metadiscourse: Exploring interaction in writing. The Modern Language Journal, 91(3), 479-480. doi: 10.1111/j.1540-4781.2007.00593_9.x

Intaraprawat, P., \& Steffensen, M. S. (1995). The use of metadiscourse in good and poor ESL essays. Journal of Second Language Writing, 4(3), 253-272. https://doi.org/10.1016/1060-3743(95)90012-8

Jiang, H., \& Bian, N. (2008). Use of metadiscourse in allocating SLA learners' attention. Sino-US English Teaching, 5(11). doi:10.17265/1539-8072/2008.11.001 
Jomaa, N. J., \& Alia, M. M. (2019). Functional analyses of metadiscourse markers in L2 students' academic writing. Arab World English Journal (AWEJ), 10(1), 361-381. https://doi.org/10.24093/awej/vol10no1.30

Karimi, K., Maleki, M., \& Farnia, M. (2017). Metadiscourse markers in the abstract sections of Persian and English law articles. International Journal of Foreign Language Teaching and Research, 5(18), 69-83. https://www.researchgate.net/publication/316167809_Metadiscourse_Markers_in_the_Abstract_Sections_of_P ersian_and_English_Law_Articles

Khedri, M., Heng, C. S., \& Ebrahimi, S. F. (2013). An exploration of interactive metadiscourse markers in academic research article abstracts in two disciplines. Discourse Studies, 15(3), 319-331. https://doi.org/10.1177/1461445613480588

Kim, C. H., \& Suh, H. W. (2014). Epistemic rhetorical stance: Hedges and boosters in L1 and L2 students' English writings. The Linguistic Association of Korea Journal, 22(2), 61-93. doi: 10.24303/lakdoi.2014.22.2.61

Kuhi, D., \& Mojood, M. (2014). Metadiscourse in Newspaper Genre: A Cross-linguistic Study of English and Persian

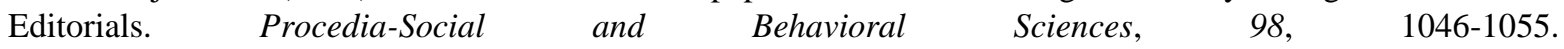
https://doi.org/10.1016/j.sbspro.2014.03.515

Marandi, S. (2003). Metadiscourse in Persian/English master's theses. Iranian Journal of Applied Linguistics, 6(2), 23-24. https://www.sid.ir/en/journal/ViewPaper.aspx?id=5105

Moghadam, F. D. (2017). Persuasion in journalism: A study of metadiscourse in texts by native speakers of English and Iranian EFL Wwriters. Theory and Practice in Language Studies, 7(6), 428-434. doi:10.17507/tpls.0706.11

Metzl, J. (2011). The protest psychosis: How schizophrenia became a black disease. New York: Beacon Press.

Oldham, J., \& Bone, S. (1994). Paranoia. Madison: International Universities Press.

Peyvastegar, M. (2012). Paranoia. Tehran: Avaye Noor Publication.

Pooresfahani, A. F., Khajavy, G. H., \& Vahidnia, F. (2012). A contrastive study of metadiscourse elements in research articles written by Iranian applied linguistics and engineering writers in English. English Linguistics Research, 1(1), 88-96. https://doi.org/10.5430/elr.v1n1p88

Samaie, M., Khosravian, F., \& Boghayeri, M. (2014). The frequency and types of hedges in research article Introductions by Persian and English native authors. Procedia-Social and Behavioral Sciences, 98, 1678-1685. https://doi.org/10.1016/j.sbspro.2014.03.593

Tavakoli, M., Amirian, Z., \& Moslemi, F. (2012). Analysis of interactional metadiscourse markers across applied linguistics disciplines: Focusing on EFL learners' perception. Iranian EFL Journal, 8(5), 99-113.

Toumi, N. (2009). A model for the investigation of reflexive metadiscourse in research articles. Language Studies Working Papers, 1, 64-73. https://www.researchgate.net/publication/285473524_A_model_for_investigation_of_reflexive_metadiscourse in research articles_University_of Reading

Yang, H. (2006). A comparative study of scientific hedging by Chinese writers and English writers. Language Education papers, 3(3), 58-62.

Yazdani, S., Sharifi, S., \& Elyassi, M. (2014). Interactional metadiscourse in English and Persian news articles about 9/11. Theory and Practice in Language Studies, 4(2), 428. https://doi.org/10.4304/tpls.4.2.428-434

Vande Kopple, W. J. (1997). Refining and Applying Views of Metadiscourse. Paper presented at the Annual Meeting of the Conference on College Composition and Communication (48th, Phoenix, AZ, March 12-15, 1997), 1-19. https://files.eric.ed.gov/fulltext/ED411539.pdf

Vande, K. W. (1984). Some exploratory discourse on metadiscourse. College Composition and Communication, 36(1), 82-93. doi: 10.2307/357609 https://www.jstor.org/stable/357609

Williams, J. (1980). Style: Ten lessons in clarity and grace. Boston: Scott Foresman. The University of Chicago Press, $1-208$. 
Zarei, G. R., \& Mansoori, S. (2007). Metadiscourse in academic prose: A contrastive analysis of English and Persian research articles. The Asian ESP Journal, http://research.iaun.ac.ir/pd/mansouri/pdfs/PaperM 9454.pdf

Zarei, G. R., \& Mansoori, S. (2011). A contrastive study on metadiscourse elements used in humanities vs. non humanities across Persian and English. English Language Teaching, 4(1), 42-50. doi: 10.5539/elt v4n1p42 
Appendix I: Frequency distribution of using instances of hedging, boostering, and self-mentioning metadiscourse markers in Persian-speaking and English-speaking contexts

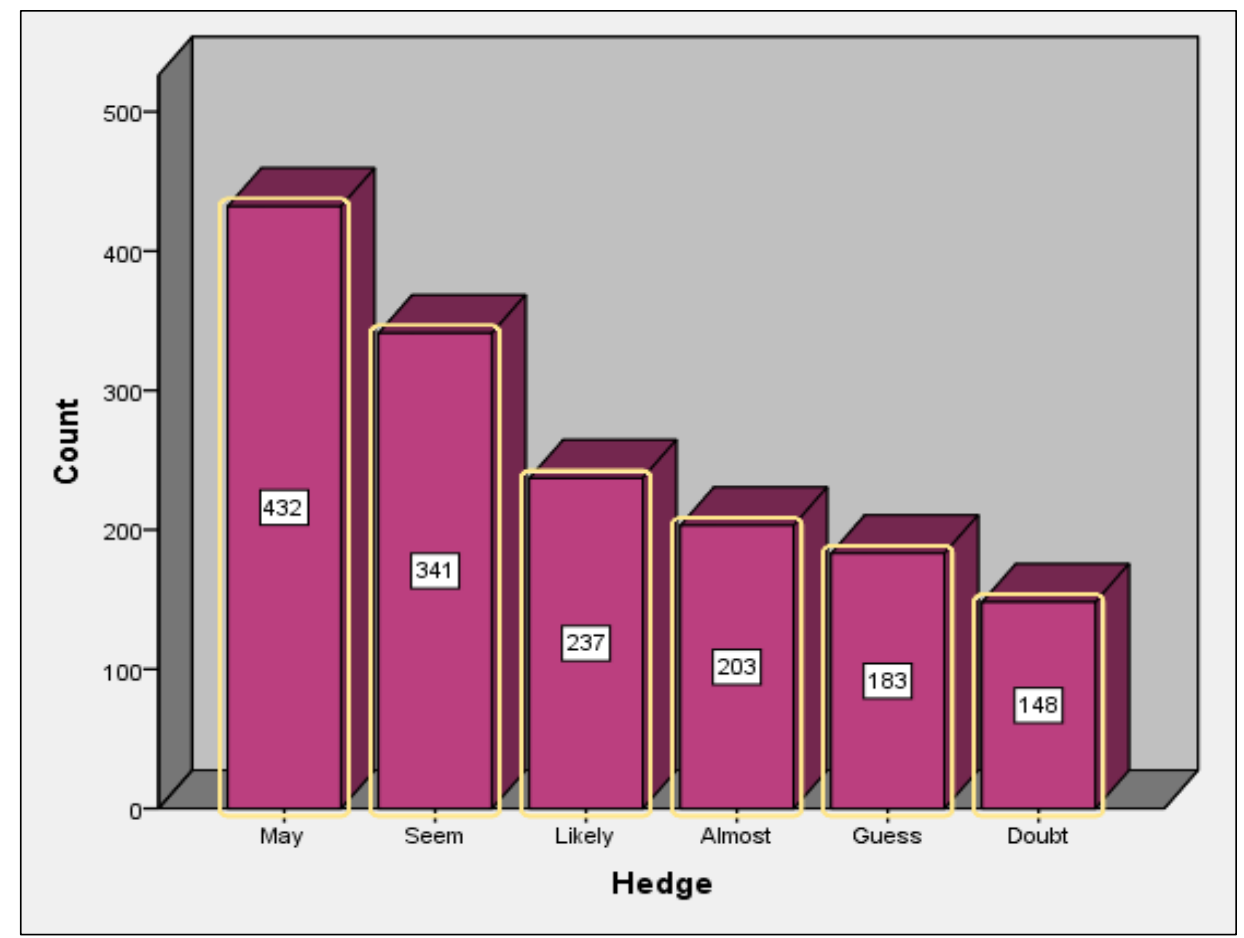

Figure 3. The frequency distribution of using instances of hedging metadiscourse markers in Persian-speaking context

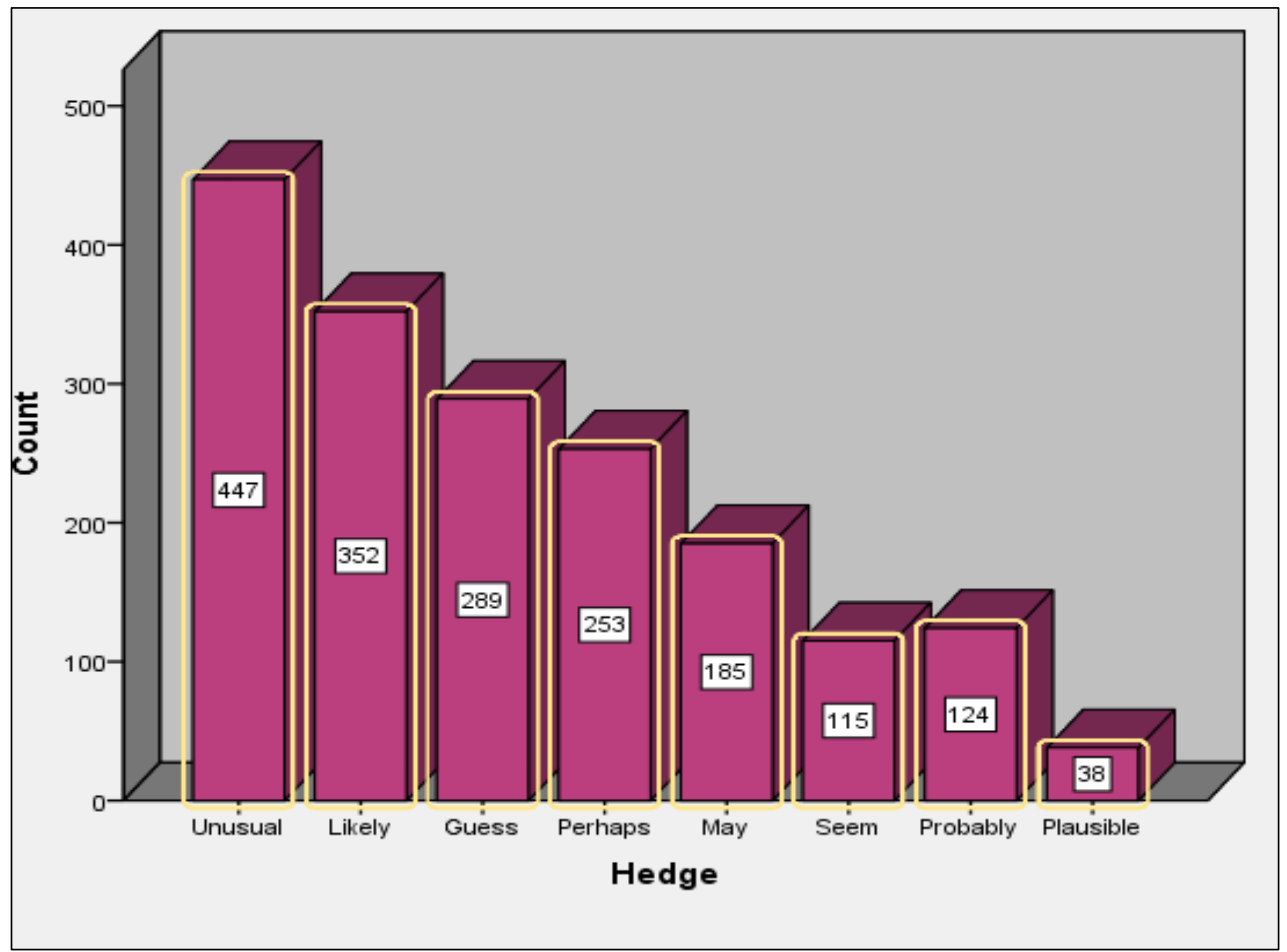

Figure 4. The frequency distribution of using instances of hedging metadiscourse markers in English-speaking context 


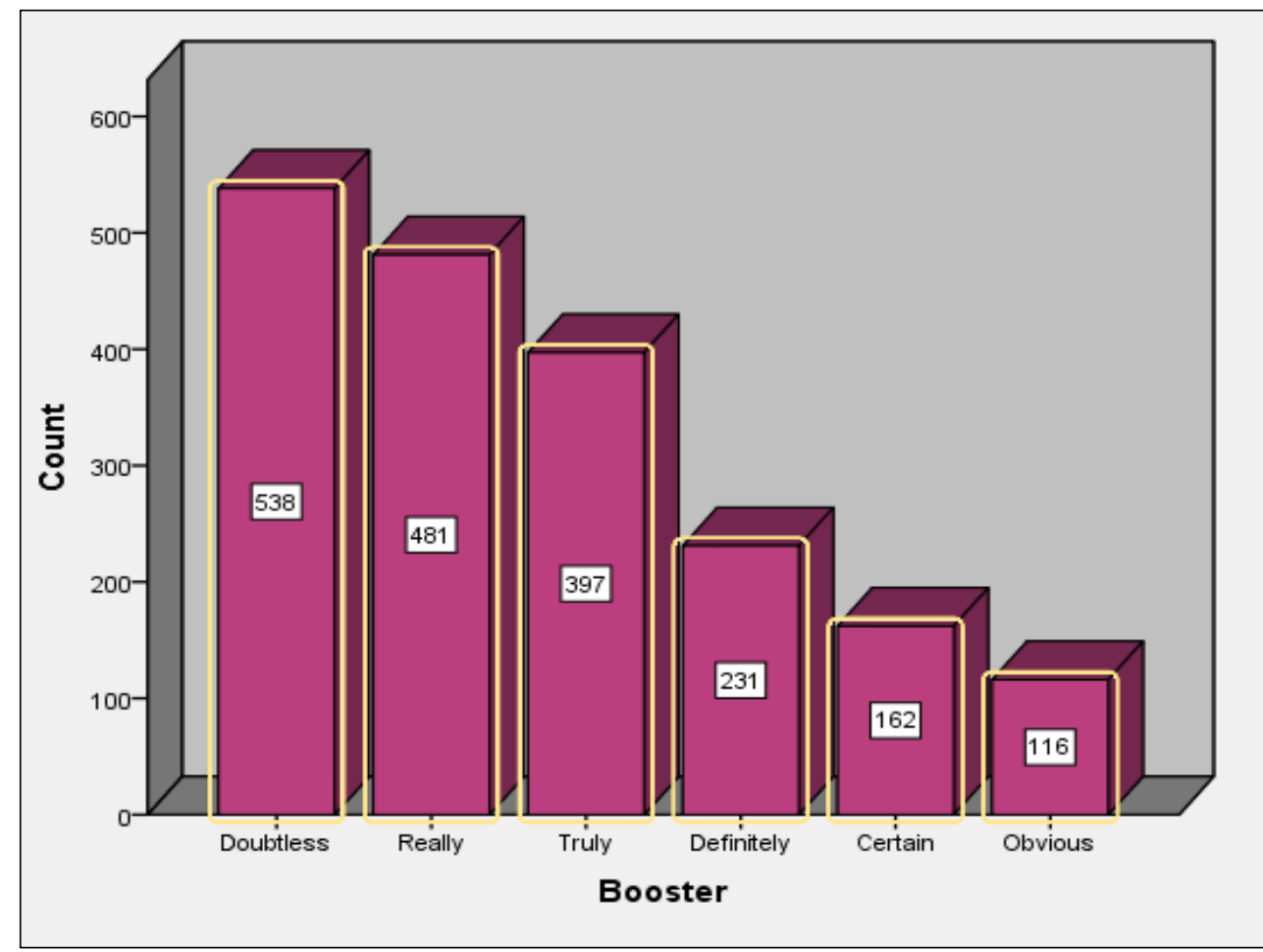

Figure 5. The frequency distribution of using instances of boostering metadiscourse markers in Persian-speaking context

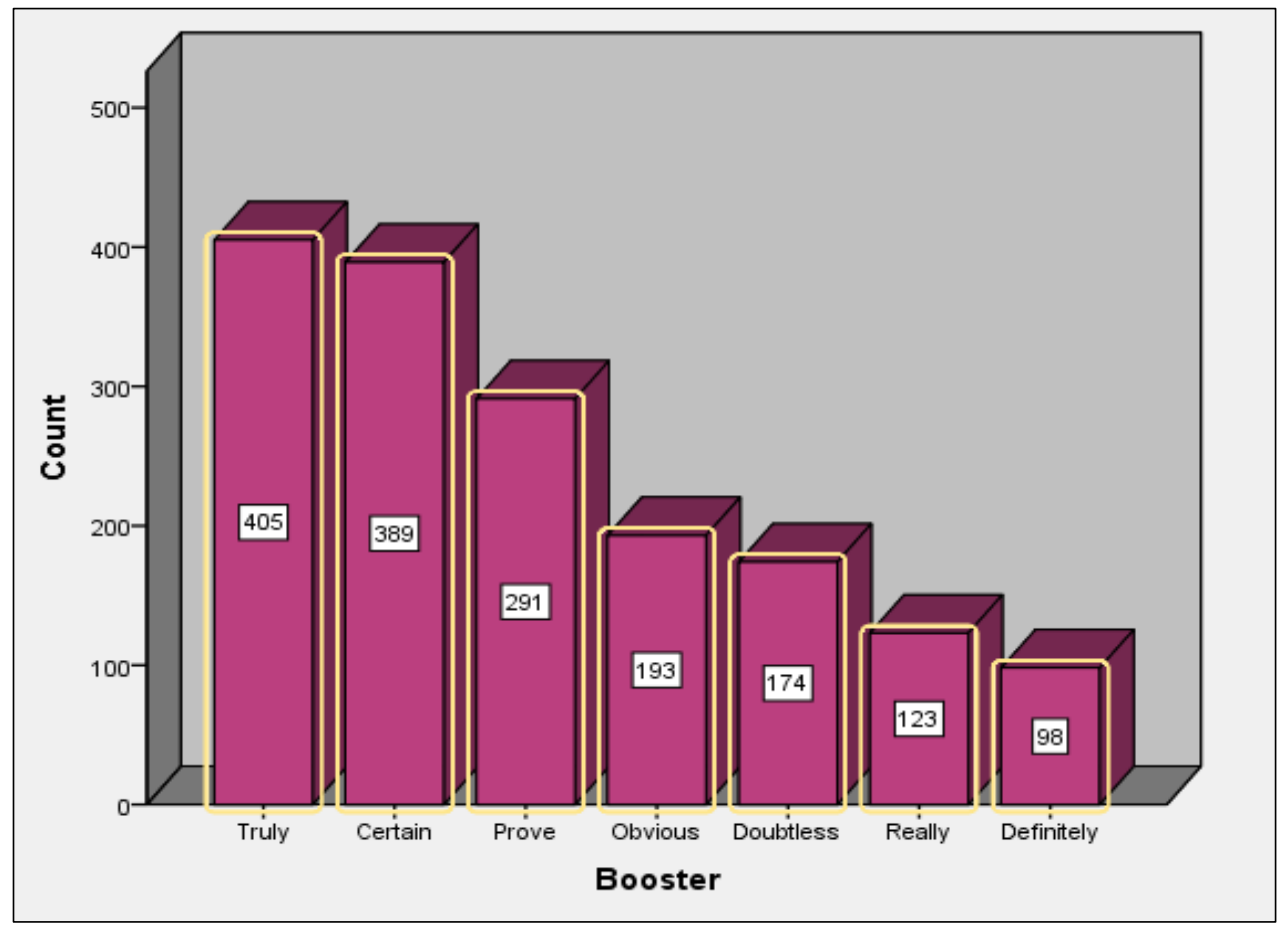

Figure 6. The frequency distribution of using instances of boostering metadiscourse markers in English-speaking context 


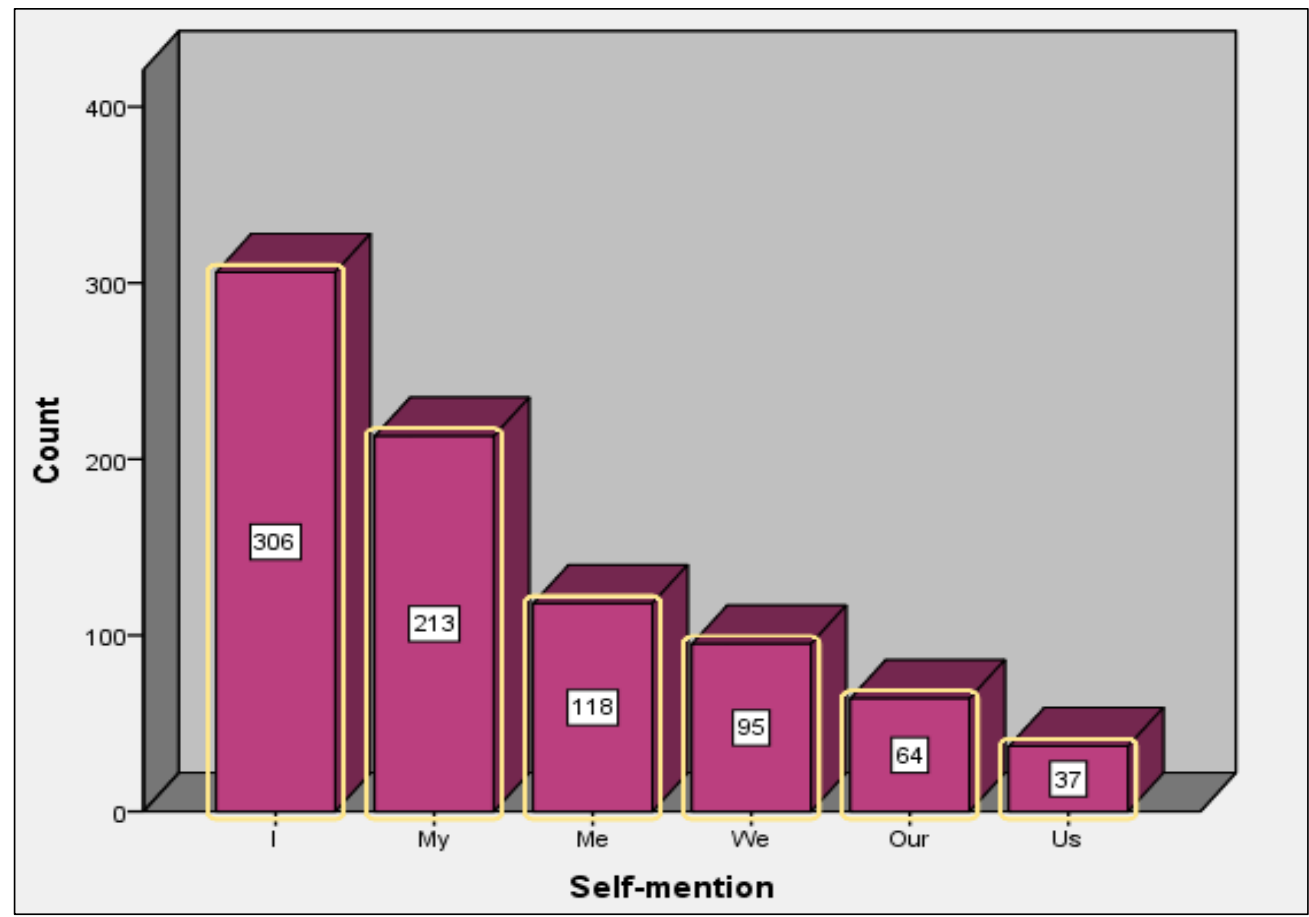

Figure 7. The frequency distribution of using instances of self-mentioning metadiscourse markers in Persian-speaking context

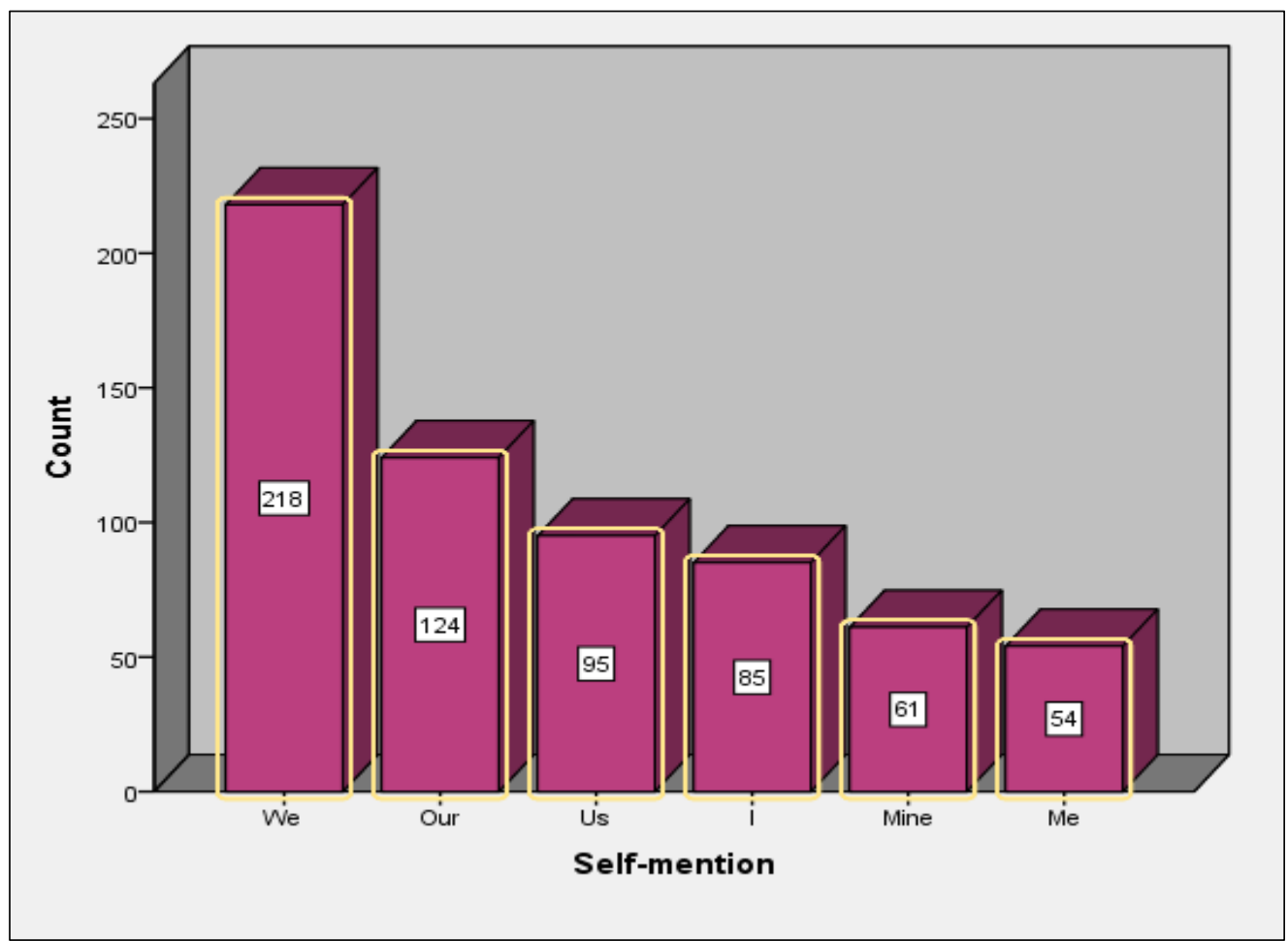

Figure 8. The frequency distribution of using instances of self-mentioning metadiscourse markers in English-speaking context 